\title{
Polysaccharides; Classification, Chemical Properties, and Future Perspective Applications in Fields of Pharmacology and Biological Medicine (A Review of Current Applications and Upcoming Potentialities)
}

\author{
Aiman Saleh A. Mohammed ${ }^{1,2}$ (D) Muhammad Naveed ${ }^{1}$. Norbert Jost ${ }^{1,3}$ \\ Accepted: 6 January 2021 / Published online: 27 January 2021 \\ ๑) The Author(s), under exclusive licence to Springer Science+Business Media, LLC part of Springer Nature 2021
}

\begin{abstract}
Polysaccharides are essential macromolecules which almost exist in all living forms, and have important biological functions, they are getting more attention because they exhibit a wide range of biological and pharmacological activities, such as anti-tumour, immunomodulatory, antimicrobial, antioxidant, anticoagulant, antidiabetic, antiviral, and hypoglycemia activities, making them one of the most promising candidates in biomedical and pharmaceutical fields. Polysaccharides can be obtained from many different sources, such as plants, microorganisms, algae, and animals. Due to their physicochemical properties, they are susceptible to physical and chemical modifications leading to enhanced properties, which is the basic concept for their diverse applications in biomedical and pharmaceutical fields. In this review, we will give insight into the most recent updated applications of polysaccharides and their potentialities as alternatives for traditional and conventional therapies. Challenges and limitations for polysaccharides in pharmaceutical utilities are discussed as well.
\end{abstract}

Keywords Carbohydrates · Polysaccharides · Biological activities $\cdot$ Pharmacological applications $\cdot$ Future prospects

\section{Introduction}

Polysaccharides are the most abundant naturally occurring macromolecular polymers which are obtained from renewable sources such as algae, plants, and microorganisms such as fungi and bacteria (Fig. 1) [1]. Together with other biomolecules like proteins and nucleotides, polysaccharides are an essential component and exert many activities in the biological system such as cell-cell communication, adhesion, and molecular recognition in the immune system [2]. Polysaccharides, which belong to the third major class of biopolymers (carbohydrates) (Fig. 2), play crucial roles in

Aiman Saleh A. Mohammed

mohammed.aiman@med.u-szeged.hu; loorka@163.com

1 Department of Pharmacology and Pharmacotherapy, Faculty of Medicine, Interdisciplinary Excellence Centre, University of Szeged, Szeged 6720, Hungary

2 Department of Pharmacology, Faculty of Pharmacy, University of Aden, Aden, Yemen

3 ELKH-SZTE Research Group of Cardiovascular Pharmacology, Szeged 6720, Hungary many different physiological processes and tumor metastasis [3], they can also provide structure, protection, adhesion, and stimuli responsiveness, they also have crucial roles in the immune system, blood clotting, fertilization, pathogenesis prevention, and therapeutic efficacy [4].

Natural polysaccharides can be obtained from different sources like algal origin, e.g., alginate, plant origin, e.g., pectin and gums, microbial origin, e.g., dextran, and animal origin, e.g., chitosan [5, 6], and can be considered as an essential functional material that plays important roles in many physiological and biological activities including antioxidant, antitumor, anti-hyperglycemic, and immune regulation activities $[7,8]$. The use of microbial polysaccharides in the field of biotechnology and biomedical sciences was started many years ago $[9,10]$. The diversity of sources that could produce polysaccharides made it a substance of choice as starting materials which were modified chemically and used in different medical and non-medical fields [11], include food, energy, wood, paper, textiles, fibers, and oil drilling $[12,13]$. 
Fig. 1 Examples of polysaccharides from different sources

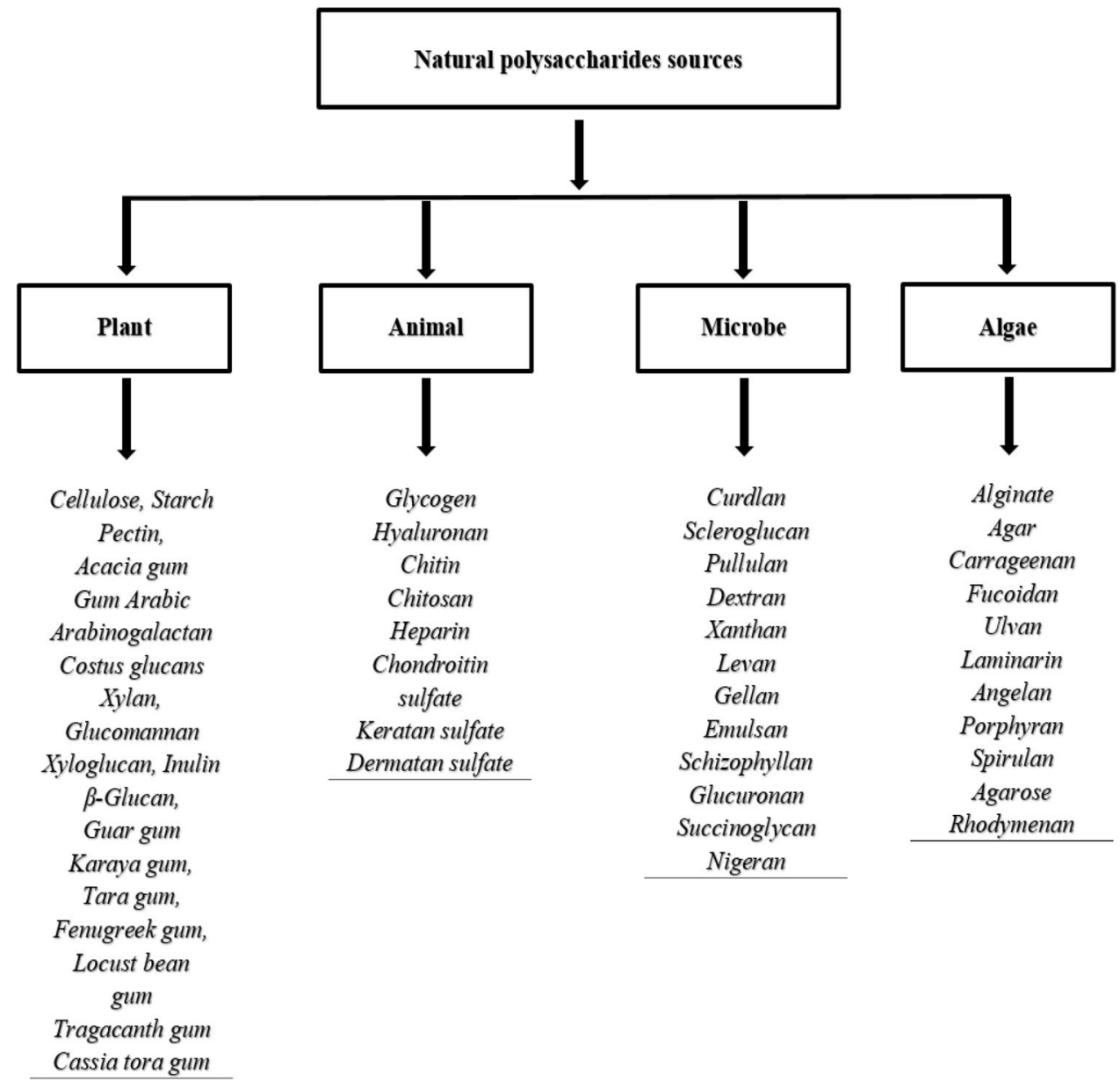

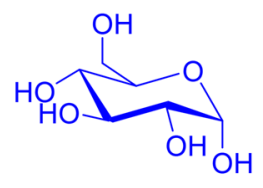
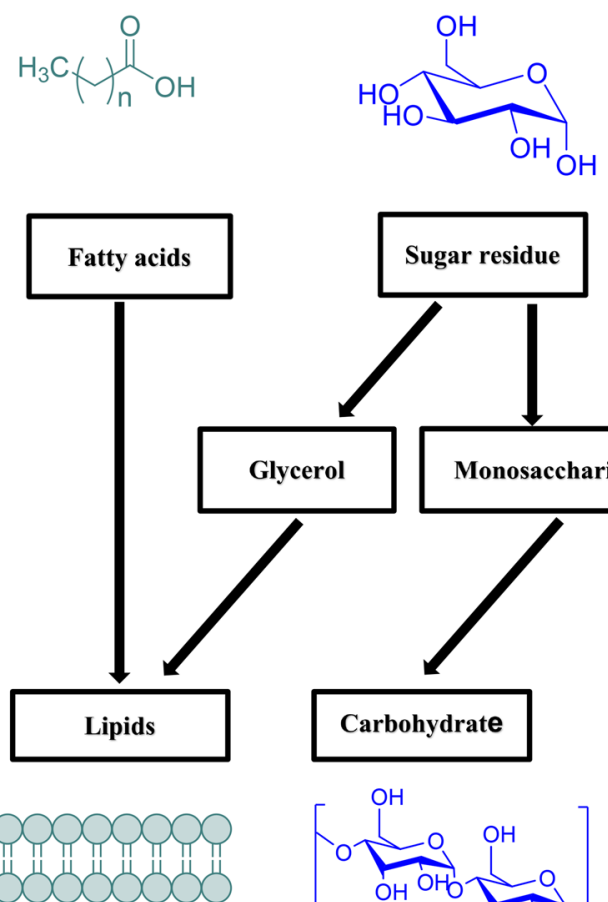

Glycerol

Carbohydrate
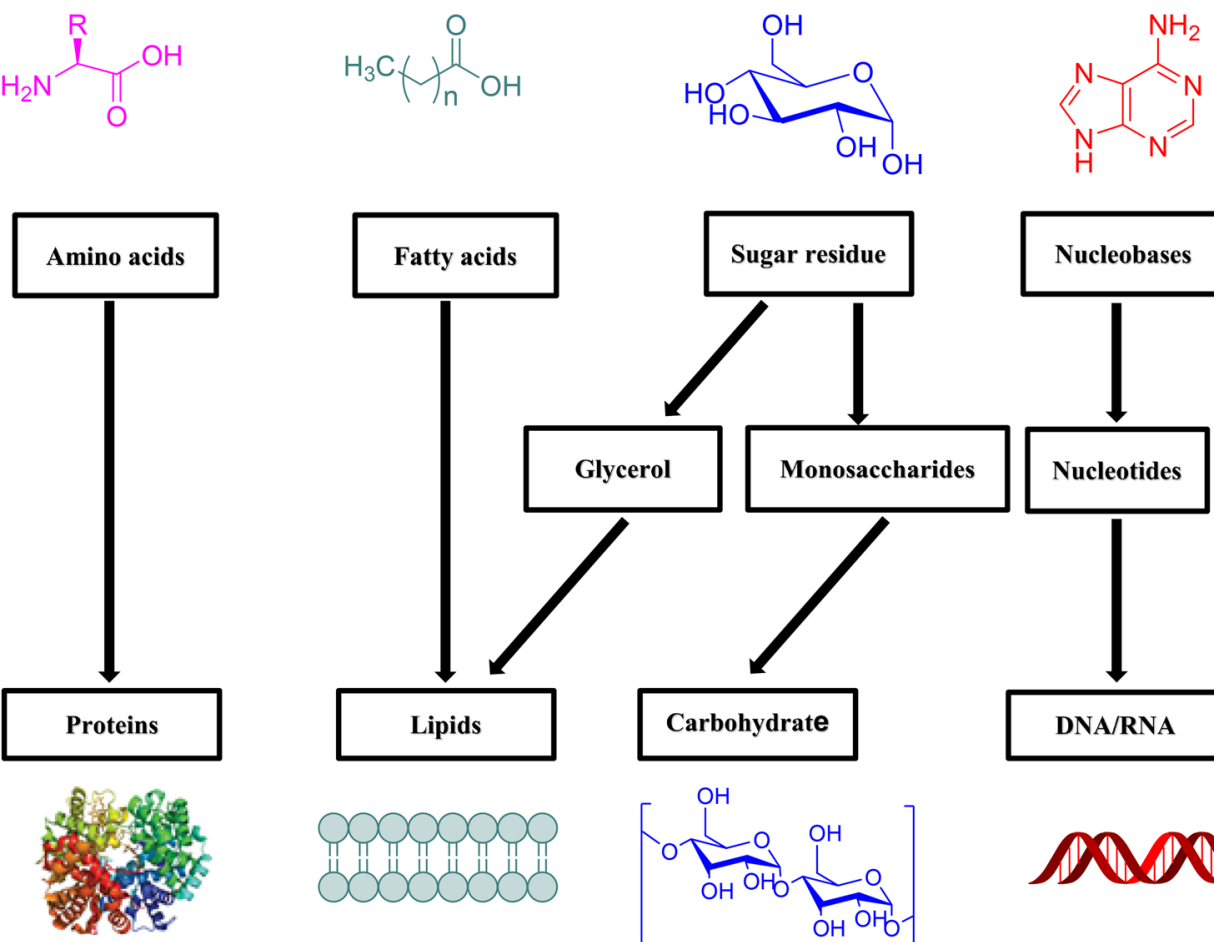

Nucleotides
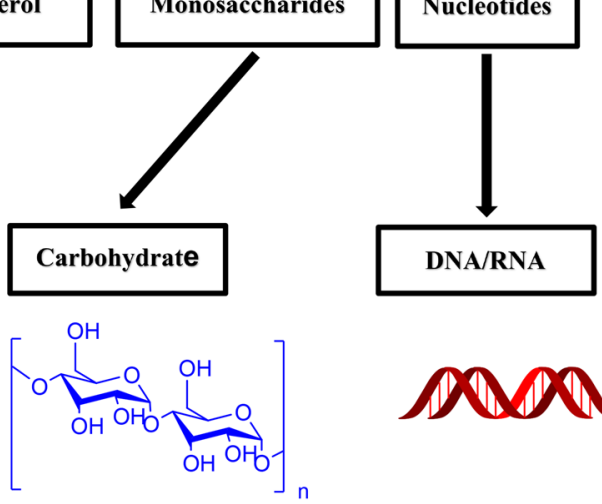


\section{Classification, Chemical Structure, Sources, and Physicochemical Properties of Polysaccharides}

Polysaccharides, the most form of carbohydrates that existed in nature [14], can be defined according to their chemical structure, which contains monosaccharides units that linked by glycosidic bonds $[15,16]$, they are either sugars residues that glycosidically linked together or bonded covalently to other structures like peptides, amino acids, and lipids. Homopolysaccharides are homoglycans that consist of the same monosaccharides, whereas heteropolysaccharides are heteroglycans that consist of different monosaccharides (Fig. 3).

Glucans are glucose homopolysaccharides, while mannans are mannose homopolysaccharides [14]. Hydrophilic groups like $\mathrm{OH}, \mathrm{COOH}$, and $\mathrm{NH}_{2}$ groups can form a bioadhesive layer with epithelial and mucous membrane tissues [5]. The most common constituent of polysaccharides is D-glucose; however, D-fructose, D-galactose, L-galactose, D-mannose, L-arabinose, and D-xylose are also frequent, some monosaccharide derivatives found in polysaccharides include the amino sugars (D-glucosamine and D-galactosamine) as well as their derivatives ( $N$-acetylneuraminic acid and $\mathrm{N}$-acetylmuramic acid), and simple sugar acids (glucuronic and iduronic acids). Polysaccharides can be differentiated according to the nature of monosaccharides components, length of chains, and the branching of those chains. The glycosidic linkage through the anomeric carbon atom between the glycosidic bond donor and the acceptor form either linear or branched chains, which make them distinguished from proteins and peptides since the latter has only linear chains. Polysaccharides naturally have storage properties like starch or structural properties, e.g., cellulose (Fig. 4), which provides physical structure and stability [14]. Polysaccharides can also be classified based on polyelectrolyte to positively charged polysaccharides (chitosan) and negatively charged polysaccharides (alginate, heparin, hyaluronic acid, and pectin [5]. Another primary components of the cell surface and the cell-extracellular matrix (ECM), Glycosaminoglycans (GAGs), they were studied extensively [17], heparin, heparan sulfate, hyaluronan, chondroitin sulfate, dermatan sulfate, and keratan sulfate are the most important GAGs polysaccharides in mammalian tissues [18], some biological importance of these GAGs will be explained in this review.

Chemical modifications of polysaccharides like sulfation, phosphorylation, and carboxymethylation are very efficient procedures to modify and change the biological properties of polysaccharides[19], which render them suitable for drug delivery systems in different drugs preparations because they can be more stable, non-toxic, and biodegradable [20]. Chemical modifications such as grafting, cross-linking, complexation, and covalent coupling add more potentialities as drug delivery and subsequently improve therapeutic efficacy [4]. They can also be a suitable choice for the replacement of some excipients or synthetic polymers [15].

Traditional polysaccharides vaccines contain contaminants and impurities in their heterogeneous mixtures; therefore, the chemically synthetic polysaccharides-based vaccine can overcome these shortcomings [21].
Fig. 3 Branched and unbranched homopolysaccharides and heteropolysaccharides, different monosaccharides represented by different colors

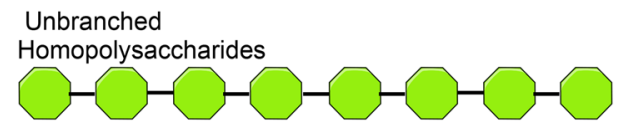

Unbranched

Hetropolysaccharides
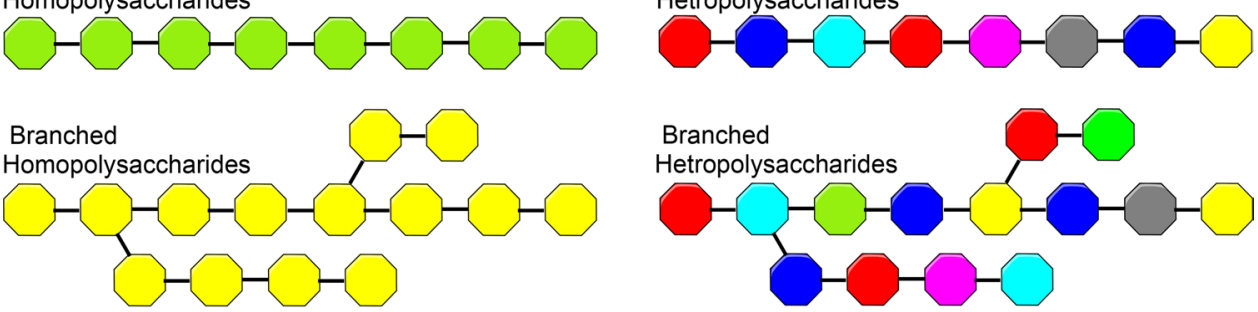

Fig. 4 Classification of polysaccharides according to the type of monosaccharides building blocks and their physiological properties

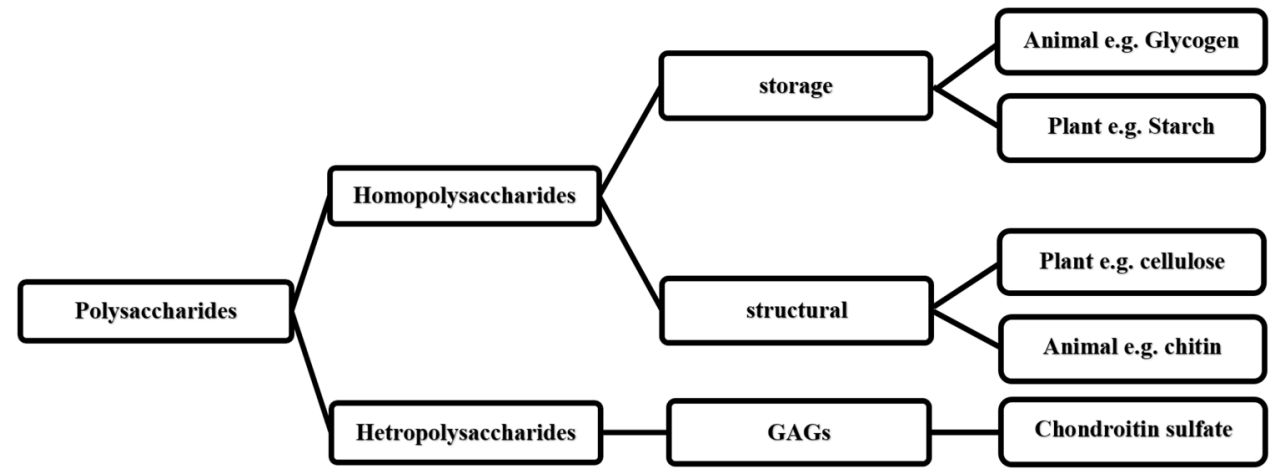


The stability, hydrophilicity, and biodegradability [22], along with other properties like the diversity of the physicochemical properties of natural polysaccharides provide the basis for its wide range of biological activities [16]. It has been established that the biochemical and physical properties of polysaccharides have been contributed to their biomedical applications [18].

\section{Polysaccharides Application}

\section{Application in Vaccine}

The immune system plays an important role in responding to different external exposures like infectious diseases, inflammatory agents, and even carcinogens. Recently, cancer and infectious diseases become an emerging problem, and due to drawbacks like resistance, toxicity, and lack of immune responses of some available drugs, pharmaceutical companies are more concerned with the discovery of new safe and effective immune-stimulating alternatives, polysaccharides in this regard, are considered one of the best choices. It was proved that polysaccharides isolated from traditional Chinese medicine could activate or regulate $\mathrm{T}$ lymphocytes and macrophages, enhance the activity of interleukin, improve the antibody level, and regulate the immune function of the organism [23]. Polysaccharides were also proved an important modulator since they can enhance immunity through different mechanisms, such as stimulation of macrophages, splenocytes, and thymocytes [24]. The carbohydrate-based vaccine is intensively studied for their potentiality to become vaccine candidates. Tumor-associated carbohydrate antigens and polysaccharides located on the surface of pathogenic microorganisms can be recognized by the host immune system [25], which opens a new era in glycobiology and vaccination availability [3] since polysaccharides have a vital role in cell-cell recognition and interaction with the immune system. Many vaccine formulations contain polysaccharidesbased antigens such as bacterial capsular polysaccharides or tumor-associated carbohydrate antigens which have been used in many vaccines formulations [26]. Since the $80 \mathrm{~s}$ of the last century, polysaccharides vaccines were available for different infectious diseases like Pneumonia and meningitis $[27,28]$. Unfortunately, conventional polysaccharide antigens (mainly high-purified capsular polysaccharides) have disadvantages such as short duration with a poor immunogenic response in infants and young children because of the absence of immunological memory and $\operatorname{IgM}$ to $\operatorname{IgG}$ class switch. To overcome these shortcomings, new polysaccharides vaccines are conjugated to strongly immunogenic protein carriers like diphtheria and tetanus toxins that induce $\mathrm{T}$ cell-dependent response and enhance the immunogenicity $[21,29]$ through interacting with the immune system [30].

\section{Biomedical Applications}

Since the last century, polysaccharides have found their place in the biomedical fields [15]. Owing to many properties of polysaccharides like biodegradability, biocompatibility, non-immunogenicity, and enhanced solubility and stability. They have been considered as potential candidates in many biomedical applications [3, 18], (Table 1). Moreover, the abundance of polysaccharides sources and their low cost made them substances of choice and used in many biomedical [31], and biotechnological applications [32]. For instance, polysaccharides obtained from algae have been extensively used in biomedical applications such as wound management, regenerative medicine and to control drug delivery [33]. The ability of polysaccharides-based biomaterials to form hydrogels is another advantage of these new emerging class of biomaterials [14], e.g., heparin-loaded hydrogels, which have been used successfully to deliver bone morphogenetic proteins [18]. The polysaccharide was proved to improve the mechanical properties [34], which can overcome the poor biological performance of synthetic polymers [35].

\section{Drugs, Vaccine Delivery, and Tissues Engineering}

Recently, polysaccharides have been extensively used as drug carriers, building blocks for drug delivery, bioactive materials, and excipients to enhance drug delivery [4], they also gain more attention in tissue engineering [63], cosmetics, and wound healing fields [12]. The ability of natural polysaccharides to be shaped and modified to do specific goals made them a potential candidate for many applications including drug and vaccine delivery. Xanthan gum, gellan gum, and scleroglucan are microorganisms-derived polysaccharides and have been studied extensively in drug delivery [64]. The absorption of the drug can be increased by loading it in bioadhesive polysaccharides nanoparticle carriers [5]. Other naturally occurring polysaccharides include pectin, guar gum, amylose, inulin, dextran, chitosan, and chondroitin sulphate, which have been investigated for colon-specific drug release and their ability to be used as pharmaceutical excipients [65]. These polysaccharides can deliver drugs to the colon as prodrugs or coating tablets $[20,66]$; moreover, chitin and chitosan are low-immunogenic and tissue compatible polysaccharides that proved to be effective in wound healing, tissue engineering, bone regeneration, and in delivery of drugs and vaccine [67, 68]. Chitosan (Fig. 5) is one of the most biopolymers that has been widely used as a drug and vaccine delivery system in many preparations [69], that is because a wide variety of antigen that could be encapsulated under mild conditions and without using organic solvents, which avoid the degradation and denaturation of the antigen during processing or after loading [68]. 


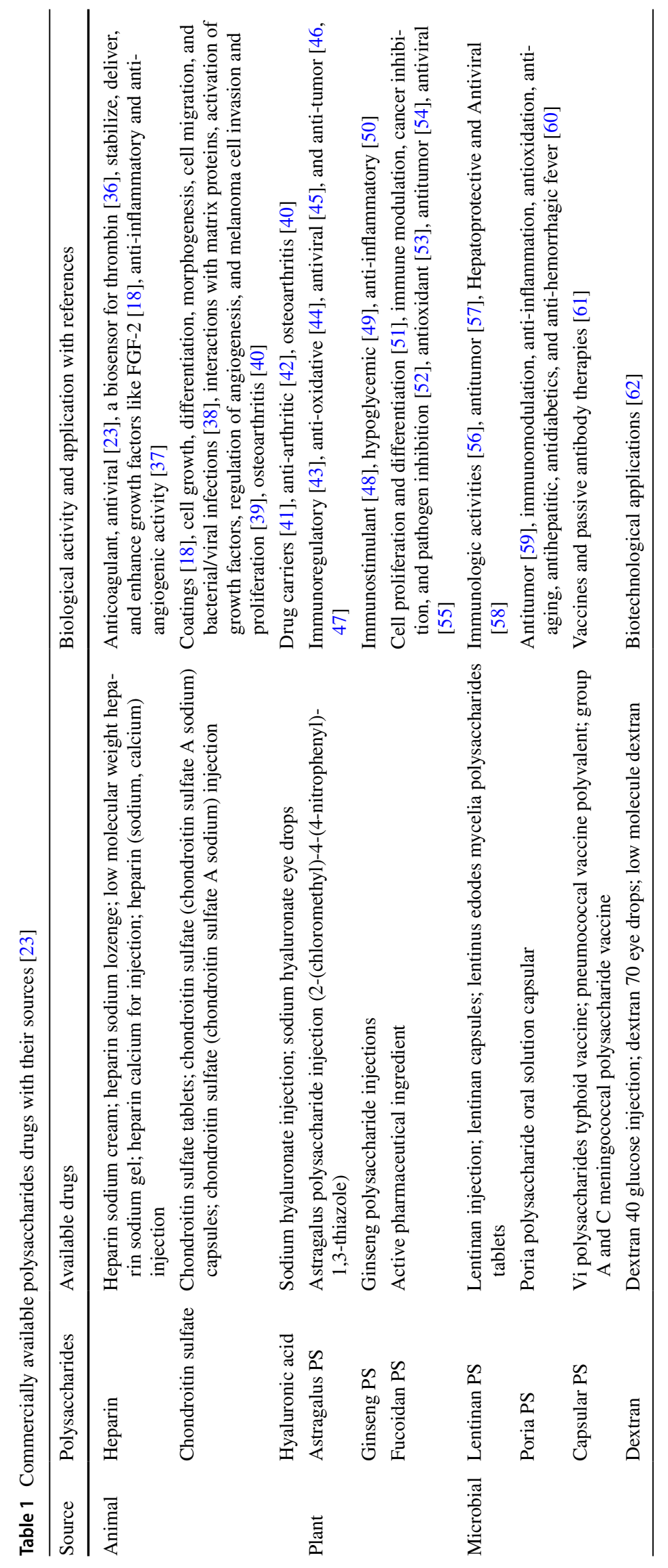




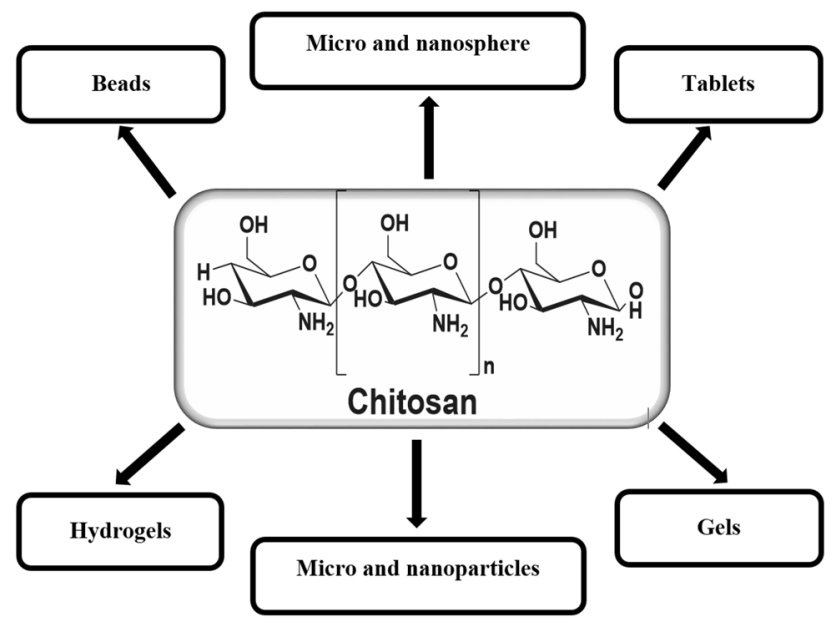

Fig. 5 Chitosan-based drug delivery systems

Polysaccharides-based nanoparticles are gaining more attention as nanometric carriers for the drug delivery system [5]. Polycations, which are prepared by reductive amination reaction between primary amines and periodate oxidized polysaccharides, are considered a new class of non-viral gene delivery systems, cationic polysaccharides are also used as gene transfection vectors [70]. Hydrogels based on cross-linked polysaccharides are used in key applications, such as drug delivery systems and tissue engineering [71], the hyper-branched polymer is considered an excellent carrier for gene delivery nanoparticles [24].

\section{Antitumor and Immunomodulatory Activities}

The tumor is a major health problem, and a leading cause of death worldwide [72] antitumor activities can be found in many plants [7] and marine polysaccharides [33]. A wide variety of natural polysaccharides proved to be effective antitumor agents, e.g., lentinan and schizophyllan [24]. It has been indicated that polysaccharide-protein conjugate has antitumor activity and can also enhance the activity of conventional chemotherapeutical drugs [72]. Recently, many researches have proved the immunosuppressive activity of polysaccharides against tumor growth [73]. Mushrooms are rich sources of many therapeutic agents and have been used for a long time as food and medicinal agents, regardless of the differences in the chemical structures and conjugated parts. It has been established that natural polysaccharides derived from mushrooms have been extensively studied for their potent antitumor and pharmaceutical activity activities $[74,75]$. Examples of polysaccharides from mushrooms include Ganoderma lucidum which proved to have potent in vitro immune activation, and antitumor activity on the breast cancer cells [76, 77], and Lentinus edodes, which exhibited a marked antitumor effect against subcutaneously transplanted sarcoma [78]. Polysaccharides derived from mushrooms can produce their antitumor effects through the following proposed mechanisms oncogenesis prevention, immune system enhancement, and induce apoptosis of tumor cells through its direct tumor-inhibitory effect [79]. Besides the antitumor activity, mushrooms polysaccharides exhibit a wide range of therapeutic activities and are used in clinical trials to increase the effectiveness of chemotherapeutic agents and minimize their side effects [80]. Algae polysaccharides are also of great importance because they have a diversity of pharmacological activities, including antitumor activity [81]. Polysaccharides activate effector cells, such as macrophages, T lymphocytes, B lymphocytes, cytotoxic T lymphocytes, and natural killer cells to express cytokines, such as TNF- $\alpha$, IFN-c, and IL- $1 \beta$, cytokines invariably possess antiproliferative activity, cause apoptosis and differentiation in tumor cells (Fig. 6), and also secrete products like reactive nitrogen, oxygen intermediates, and interleukins [82]. Nanoparticles covered with saccharides display a higher circulation lifetime in the bloodstream. Additionally, they significantly accumulate in tumor tissues [83].

\section{Antioxidative Applications}

Reactive oxygen species (ROS) may cause damages to the human body, they attack different macromolecules such as membrane lipids, proteins, and DNA, leading to many health disorders such as cancer, diabetes mellitus, neurodegenerative and inflammatory diseases with severe tissue injuries. Antioxidative agents are of great benefit in this regard since they can block or reduce the effect of these hazardous agents [84, 85], and improve human health [86]. Antioxidants from scientific resources are bearing many drawbacks like their carcinogenesis and liver damages; for these reasons, an alternative natural substitute will be of great advantage. Polysaccharides derived from plants are promising candidates because they exhibit strong antioxidant activities [87], that could protect the human body against free radicals and decreased the complications of many diseases [88]. Owing to its biological importance, chemical properties of plant polysaccharides have been extensively investigated for their wide range of applications, such as antitumor, immunestimulation, and antioxidant activities [89]. Moreover, the existence of natural antioxidants capable of scavenging these ROS will offer great help in this regard, this is the case with polysaccharides since they possess antioxidant activity which has been proved to protect and inhibit cardio and cerebrovascular disease caused by free radicals [24]. Many of these natural polysaccharides, such as Hyriopsis cumingii, were evaluated for their antioxidative ability against different types of free radicals [90].

Another example is the polysaccharides derived from the traditional Chinese medicinal herb Astragalus, which 
Fig. 6 Possible immune mechanism cytokines a fungus polysaccharides increased the production of IL-2, 3, 4, 6, 8, and 12, TNF- $\alpha$, IFN- $\gamma$, IL- $1 \alpha$, and IL- $1 \beta$ generated from $\mathrm{T}$ cells. Cytokines b mushroom polysaccharides increased the production of IL-1, 2, 3, 12, TNF- $\alpha$, and IFN- $\gamma$ of NK cells. Cytokines $\mathbf{c}$ fungus polysaccharides could improve the release of IL- 6 and 8 , IL- $1 \beta$, TNF- $\alpha$, and IFN- $\gamma$ from macrophages. ConA was used as a specific $\mathrm{T}$ cell activator, and LPS was used as a general activator of $B$ cells, macrophages, and DCs [82]

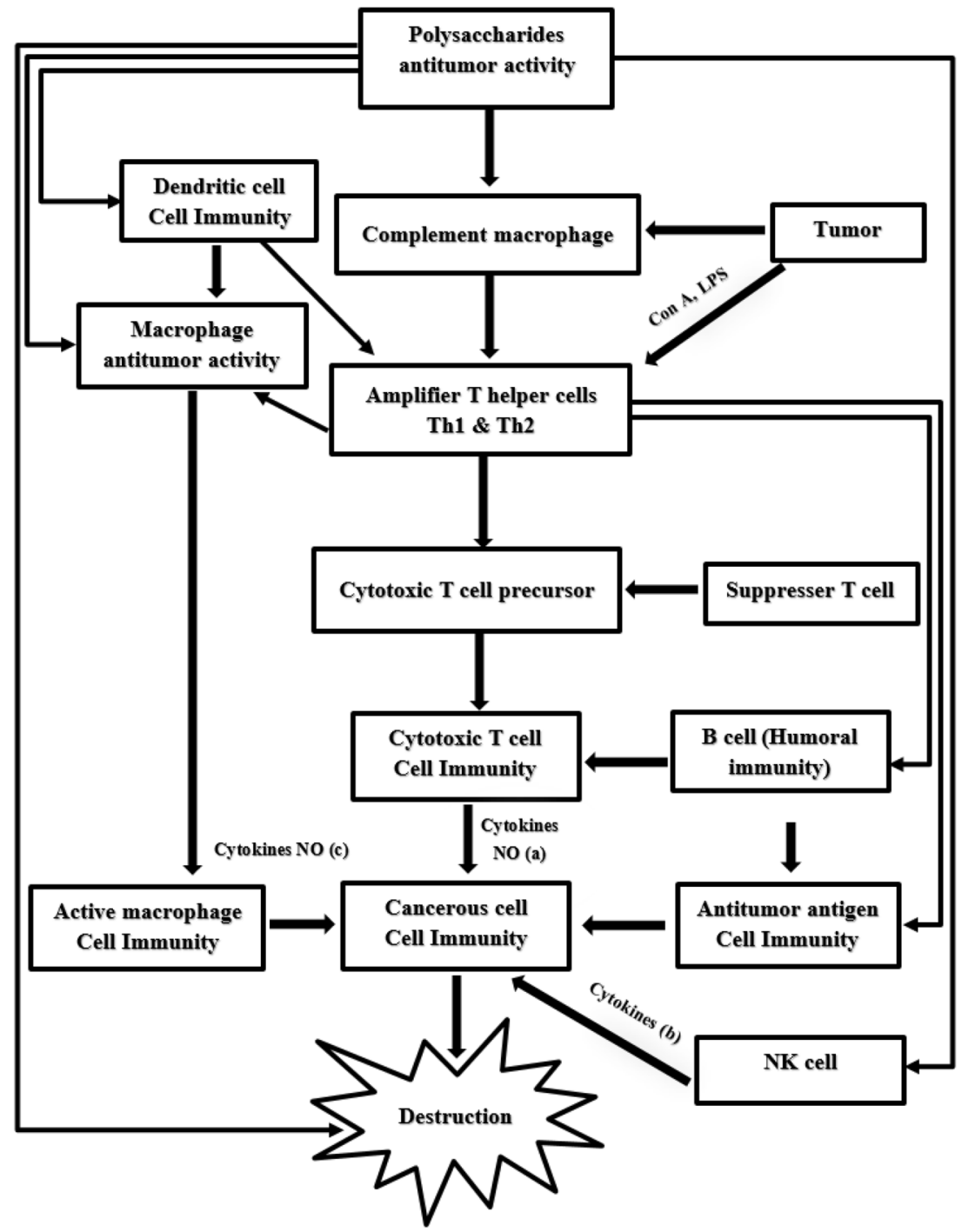

showed potent antioxidant and antitumor activity [91]. Sulfated polysaccharides derived from seaweed and red alga also possess many activities like anticoagulant/antithrombotic, antiviral, immuno-inflammatory, antilipidemic, and antioxidant activities [92, 93]. Antioxidative properties of polysaccharides are well proved, different kinds of polysaccharides have been used for this purpose include seaweed polysaccharides, e.g., sulfated polysaccharides, plant polysaccharides, e.g., arabinogalactan, galactomannan, and pectic polysaccharides, and mushroom polysaccharides, e.g., $\beta$-glucans and glycoproteins [23].

\section{Other Applications}

\section{Anti-inflammatory Activity}

Natural polysaccharides have been widely used in nanomaterials for controlling inflammatory pathologies [15], and were experimentally tested for their anti-inflammatory activities
[94]. The anti-inflammatory effect of polysaccharides could be through one of these mechanisms, e.g., the anti-inflammatory activity of TCM polysaccharides is mainly due to the inhibition of the expression of the chemotactic factor and adherence factor, as well as the activities of key enzymes in the inflammation process [19]. Other polysaccharides have an inhibitory effect on inflammatory-related mediators such as cytokines (IL-1b, IL-6, TNF-a) and NO (nitric oxide), and decreased the infiltration of inflammatory cells [50], sulfated polysaccharides derived from algae exhibit their antiinflammatory effect through interfering with the migration of leukocytes to sites of inflammation [92].

\section{Hypoglycemic and Hypocholesterolemic Activities}

Since the 1980s of the last century, polysaccharides have been extensively investigated in clinical trials for their hypoglycemic and hypocholesterolemic effect, Ganoderma atrum polysaccharide has potential for the treatment of 
hyperglycemia, hyperlipidemia, hyperinsulinemia, and insulin resistance, as well as a protective effect on kidney injury in the second type diabetes [24, 95]. Natural polysaccharides can be used as nanocarriers for proteins that enhance the stability of loaded proteins and prolong their therapeutic effect, e.g., the bioavailability of orally administrated Insulin-loaded dextran-chitosan nanoparticulate polyelectrolyte complex is increased with extended hypoglycemic effect [4]. Other examples of polysaccharides with hypoglycemic and hypocholesterolemic effects include sulfated polysaccharides extract from Bullacta exarate [23], chitosan [96], and Kefiran [97]. Traditional Chinese medicine derived from Tremella fuciformis Mushrooms polysaccharides showed a significant dose-dependent hypoglycemic effect and improved insulin sensitivity by regulating PPAR- $\gamma$-mediated lipid metabolism when it was administered to mice [73].

\section{Anticoagulant Activity}

Among the diversity of polysaccharides properties, anticoagulant activity was extensively studied, unfractionated and low molecular weight heparins are sulfated polysaccharides that used as anticoagulant drugs, but unfortunately, they have side effects like bleeding and thrombocytopenia [81]. It was proved that polysaccharides, specially sulfated polysaccharides, have many biological activities like anti-tumor, antioxidant, and anticoagulant activities [23]. The high content of sulfate is a key factor in the anticoagulant activity of these sulfated polysaccharides [98]. Natural polysaccharides obtained from different marine sources like shellfish (shrimp, crab, squilla, lobster, and crayfish, etc.), marine macroalgae (seaweeds), marine fungi, microalgae, and corals [99], and plant-derived polysaccharide, e.g., pectin, could be considered as potential anticoagulant agents [100].

\section{Antiviral Activity}

The antiviral activity of polysaccharides was proved since the $50 \mathrm{~s}$ of the last century, it has been established that sulfated polysaccharides from seaweeds have an inhibitory effect against the replication of enveloped viruses including herpes simplex virus (HSV), human immunodeficiency virus (HIV), human cytomegalovirus, dengue virus, and respiratory syncytial virus [92]. Different microalgae species can produce sulfated exopolysaccharides which play an important biological role as antiviral agents [98]. Polysaccharides derived from Chinese traditional medicine have also been used for a long time as antiviral agents since they can improve and strengthen the immune system through activating macrophagocytes to promote their phagocytic ability and induce the secretion of IL-2, IFN- $\gamma$, and antibodies [19]. Microalgae polysaccharides also possess a lot of biological properties, such as antioxidant, antibacterial, and antiviral activity [32].

\section{Polysaccharides in Coronavirus Disease (COVID-19)}

Undoubtedly, the Covid-19 outbreak has become a major health challenge, especially with continuous searching for safe and effective therapeutic agents and vaccines [101]. Polysaccharides with their broad antiviral activity are considered one of the promising candidates in COVID-19 prevention and control from both sides as a therapeutic agent and carriers. GAGs, Traditional Chinese Medicine, and marine polysaccharides have shown potent anti-coronavirus activity. The entry of the virus to the host cell can be interfered with by sulfated polysaccharides by blocking the positive charge of the pathogen surface receptors. The cationically modified chitosan shows significant inhibition against the human coronavirus HCoV-229E, HCoV-OC43, HCoV-NL63, and HCoV-HKU1, which indicate its inhibitory effect against low-pathogenic human coronaviruses. Traditional Chinese herbal medicine contains potential anti-SARS-CoV-2 active compounds, especially Hedysarummultijugummaxim, coptidis rhizoma, and forsythiae fructus [102]. In vitro experiments show that sulfated polysaccharides bind tightly to the S-protein of SARS-CoV-2, this interfering of protein binding to the heparan sulfate co-receptors has a potent inhibitory effect on viral infection [103]. Polysaccharides from different origins have also shown anti-pulmonary fibrosis activities, which render them an alternative agent for preventing or treating pulmonary fibrosis in COVID-19 patients [104]. One of the most complications of COVID-19 is the susceptibility of the infected patients to the bacterial secondary infection, polysaccharides can play a major role in this regard such as Glycyrrhiza polysaccharide displayed antimicrobial activity, inhibiting the growth of B. cereus, Staphylococcus aureus, E. Aerogens, and Escherichia coli. The purified Chinese yam polysaccharide showed inhibitory activity against $E$. coli, with a minimum inhibitory concentration (MIC) of $2.5 \mathrm{mg} / \mathrm{mL}$. A recent study found that Poria cocos polysaccharide could inhibit the growth of $S$. aureus and E. coli. Asarum polysaccharides in the Lung Cleansing and Detoxifying Decoction play an important role in relieving cough symptoms, which are prevalent in COVID19 patients [105].

\section{Polysaccharides, Future Prospective, Limitations, and Challenges}

Polysaccharides are the most abundant natural biopolymers, and recently they have gained more attention as applicable substances in different biomedical areas. Many properties 
are contributed to their excellent reputation, they are economically cheaper, could be modified chemically to suit specific purposes, and unlike synthetic biopolymers which have many drawbacks such as toxicity and long-time synthetic approaches, polysaccharides are comparably safe [106]. Another advantage of Polysaccharides is their resemblance to biological macromolecules like the natural extracellular matrix (ECM), which increases the potentiality for using them in cell therapy approaches [1]. Over the past few years, there has been an increasing interest in the application of polysaccharide materials in the field of tissue engineering [107]. Mushrooms have been used for a long time, and recently they have gained more importance in cancer therapy, polysaccharides derived from mushrooms such as chizophyllan, lentinan, grifolan, polysaccharide-peptide complex (PSP), and polysaccharide-protein complex (PSK) can induce the immune response and produce the antitumor effect, which makes them promising candidates against tumor in the future [79]. The safety of polysaccharides is a crucial factor, and a strong advantage that will make the use of their increase in the future, many other organic synthesis and chemical modifications caused severe environmental pollution which could be improved by substitution to natural polysaccharides [108]. From the drug delivery perspective, and due to their biocompatibility and biodegradability properties, polysaccharides have been increasingly used in many different forms to control the delivery of some drugs [109]. The diversity of functional groups located on polysaccharides structures such as hydroxyl, amino, and carboxylic acid groups could be furtherly modified to serve as a specific biological tool in different fields like vaccine adjuvants, drug carriers, tissue engineering scaffolds, and many other pharmacological activities [110]. Natural polysaccharides such as glycogen, cellulose, and starch were engineered onto biologically superior molecules by numerous methods such as chemical modification, co-polymer grafting, and atom transfer radical polymerization (ATRP) to promote its candidature in biopharmaceutics [9]. The conjugation between hydrophilic groups of polysaccharides with hydrophobic groups of drugs can form prodrugs with amphiphilic properties, which can be self-assembled to form nanostructures with improved water solubility [83]. On the other hand, and since the polysaccharides are usually derived from natural sources, there are some limitations and challenges for polysaccharides in pharmaceutical and biological fields, such as batch-to-batch variations, microbial contamination, reduced viscosity during the storage, thickening, and uncontrolled rate of hydration. Fortunately, these drawbacks could be minimized by modifications such as grafting, cross-linking, and blending with other natural/synthetic/semi-synthetic polymers [111]. The high variability of polysaccharides in nature adds a new difficult task in extraction and purification of these polysaccharides, over and above, polysaccharides naturally found in complex with other compounds like proteins and lipids, and their isolation requires efficient and precise methods to avoid co-extraction and contamination with other compounds. Finally, the determination and fully understand of the structural activity relationship of polysaccharides shall provide new opportunities in pharmaceutical and biological applications [112].

\section{Conclusion}

Polysaccharides are the most available natural biopolymers with diverse physical and chemical properties that render them a promising candidate in many biomedical areas. Polysaccharides have several advantages over other synthetic polymers; they are safe, economical, stable, hydrophilic, biocompatible, biodegradable, and prone to chemical modifications and tailoring for specific purposes in a wide variety of applications, such as preparation of pharmaceutical materials, drug release agent and plasma substitutes. Polysaccharides can be applied biologically in many different therapeutic fields like immunoregulatory, anti-tumor, anti-virus, anti-inflammatory, antioxidation, and hypoglycemic activity. Over the past decades, polysaccharides have attracted extensive attention and can be considered as one of the most potent alternatives to conventional therapy. Even though carbohydrate-based pharmaceuticals are proved effective in different areas, they are not gaining as much interest as proteins or nucleic acid-based drugs. At the end of this review, we recommend further studies and investigation because many discoveries still lie ahead and many biological activities of a variety of polysaccharides are still not fully understood. Extensive investigation and elucidation of the structural activity relationship of polysaccharides are crucial to give more insight into the exact mechanisms of their biological activities and fully explore their future applications.

Acknowledgements This work was supported by grants from the Stipendium Hungaricum Program offered by the Hungarian State (for ASAM and MN), National Research Development and Innovation Office (GINOP-2.3.2-15-2016-00006 project for NJ), the Ministry of Human Capacities Hungary (20391-3/2018/FEKUSTRAT and EFOP3.6.2-16-2017-00006 for NJ), and from the Eötvös Loránd Research Network-Hungarian Academy of Sciences.

\section{Compliance with Ethical Standards}

Conflict of Interest The authors declare that there are no conflicts of interest.

\section{References}

1. Darge HF, Andrgie AT, Tsai HC, Lai JY (2019) Polysaccharide and polypeptide based injectable thermo-sensitive hydrogels for 
local biomedical applications. Int J Biol Macromol 133:545563. https://doi.org/10.1016/j.ijbiomac.2019.04.131

2. Yang L, Zhang LM (2009) Chemical structural and chain conformational characterization of some bioactive polysaccharides isolated from natural sources. Carbohydr Polym 76:349-361. https://doi.org/10.1016/j.carbpol.2008.12.015

3. Zhang Y, Wang F (2015) Carbohydrate drugs: current status and development prospect. Drug Discov Ther 9:79-87. https ://doi.org/10.5582/ddt.2015.01028

4. Ngwuluka NC (2018) Responsive polysaccharides and polysaccharides-based nanoparticles for drug delivery. Elsevier, Amsterdam

5. Liu Z, Jiao Y, Wang Y, Zhou C, Zhang Z (2008) Polysaccharides-based nanoparticles as drug delivery systems. Adv Drug Deliv Rev 60:1650-1662. https://doi.org/10.1016/j. addr.2008.09.001

6. Rajalekshmy GP, Lekshmi Devi L, Joseph J, Rekha MR (2019) An overview on the potential biomedical applications of polysaccharides. Elsevier, Amsterdam

7. Guo H, Zhang W, Jiang Y, Wang H, Chen G, Guo M (2019) Physicochemical, structural, and biological properties of polysaccharides from dandelion. Molecules. https://doi. org/10.3390/molecules24081485

8. Michaud P (2018) Polysaccharides from microalgae, what's future? Adv Biotechnol Microbiol 8:1-2. https://doi. org/10.19080/AIBM.2018.08.555732

9. Gopinath V, Saravanan S, Al-Maleki AR, Ramesh M, Vadivelu J (2018) A review of natural polysaccharides for drug delivery applications: special focus on cellulose, starch and glycogen. Biomed Pharmacother 107:96-108. https://doi.org/10.1016/j. biopha.2018.07.136

10. Sutherland IW (1998) Novel and established applications of microbial polysaccharides. Trends Biotechnol 16:41-46. https ://doi.org/10.1016/S0167-7799(97)01139-6

11. Liebert T, Hänsch C, Heinze T (2006) Click chemistry with polysaccharides. Macromol Rapid Commun 27:208-213. https ://doi.org/10.1002/marc.200500686

12. Bragd PL, Van Bekkum H, Besemer AC (2004) TEMPOmediated oxidation of polysaccharides: survey of methods and applications. Top Catal 27:49-66. https://doi.org/10.1023/ B:TOCA.0000013540.69309.46

13. McClements DJ (2006) Non-covalent interactions between proteins and polysaccharides. Biotechnol Adv 24:621-625. https ://doi.org/10.1016/j.biotechadv.2006.07.003

14. D’Ayala GG, Malinconico M, Laurienzo P (2008) Marine derived polysaccharides for biomedical applications: chemical modification approaches. Molecules 13:2069-2106. https ://doi.org/10.3390/molecules13092069

15. Muhamad II, Lazim NAM, Selvakumaran S (2019) Natural polysaccharide-based composites for drug delivery and biomedical applications. Elsevier, Amsterdam

16. Mizrahy S, Peer D (2012) Polysaccharides as building blocks for nanotherapeutics. Chem Soc Rev 41:2623-2640. https:// doi.org/10.1039/c1cs15239d

17. Sasisekharan R, Raman R, Prabhakar V (2006) Glycomics approach to structure-function relationships of glycosaminoglycans. Annu Rev Biomed Eng 8:181-231. https://doi. org/10.1146/annurev.bioeng.8.061505.095745

18. Boddohi S, Kipper MJ (2010) Engineering nanoassemblies of polysaccharides. Adv Mater 22:2998-3016. https://doi. org/10.1002/adma.200903790

19. Chen Y, Yao F, Ming K, Wang D, Hu Y, Liu J (2016) Polysaccharides from traditional Chinese medicines: extraction, purification, modification, and biological activity. Molecules. https ://doi.org/10.3390/molecules21121705
20. Sinha VR, Kumria R (2001) Polysaccharides in colon-specific drug delivery. Int J Pharm 224:19-38. https://doi.org/10.1016/ S0378-5173(01)00720-7

21. Nikolaev AV, Sizova OV (2011) Synthetic neoglycoconjugates of cell-surface phosphoglycans of Leishmania as potential antiparasite carbohydrate vaccines. Biochem 76:761-773. https:// doi.org/10.1134/S0006297911070066

22. Akhtar M, Ding R (2017) Covalently cross-linked proteins \& polysaccharides: formation, characterisation and potential applications. Curr Opin Colloid Interface Sci 28:31-36. https://doi. org/10.1016/j.cocis.2017.01.002

23. Yu Y, Shen M, Song Q, Xie J (2018) Biological activities and pharmaceutical applications of polysaccharide from natural resources: a review. Carbohydr Polym 183:91-101. https://doi. org/10.1016/j.carbpol.2017.12.009

24. Chen L, Ge MD, Zhu YJ, Song Y, Cheung PCK, Zhang BB et al (2019) Structure, bioactivity and applications of natural hyperbranched polysaccharides. Carbohydr Polym 223:115076. https ://doi.org/10.1016/j.carbpol.2019.115076

25. Mohammed ASA, Tian W, Zhang Y, Peng P, Wang F, Li T (2020) Leishmania lipophosphoglycan components: a potent target for synthetic neoglycoproteins as a vaccine candidate for leishmaniasis. Carbohydr Polym 237:116120. https://doi.org/10.1016/j. carbpol.2020.116120

26. Morelli L, Poletti L, Lay L (2011) Carbohydrates and immunology: synthetic oligosaccharide antigens for vaccine formulation. Eur J Org Chem. https://doi.org/10.1002/ejoc.201100296

27. Nair M (2012) Protein conjugate polysaccharide vaccines: challenges in development and global implementation. Indian J Commun Med 37:79-82. https://doi.org/10.4103/0970-0218.96085

28. Jennings HJ (1990) Capsular polysaccharides as vaccine candidates. Curr Top Microbiol Immunol 150:97-127. https://doi. org/10.1007/978-3-642-74694-9_6

29. Finn A (2004) Bacterial polysaccharide-protein conjugate vaccines. Br Med Bull 70:1-14. https://doi.org/10.1093/bmb/ldh02 1

30. Ferreira SS, Passos CP, Madureira P, Vilanova M, Coimbra MA (2015) Structure-function relationships of immunostimulatory polysaccharides: a review. Carbohydr Polym 132:378-396. https ://doi.org/10.1016/j.carbpol.2015.05.079

31. Lapasin R, Pricl S, Lapasin R, Pricl S (1995) Industrial applications of polysaccharides. Rheol Ind Polysaccharides Theory Appl. https://doi.org/10.1007/978-1-4615-2185-3_2

32. Usman A, Khalid S, Usman A, Hussain Z, Wang Y (2017) Algal polysaccharides, novel application, and outlook. Algae based polym blends. Compos Chem Biotechnol Mater Sci. https://doi. org/10.1016/B978-0-12-812360-7.00005-7

33. De Jesus Raposo MF, De Morais AMB, De Morais RMSC (2015) Marine polysaccharides from algae with potential biomedical applications. Mar Drugs 13:2967-3028. https://doi.org/10.3390/ md13052967

34. Gandini A, Lacerda TM, Carvalho AJF, Trovatti E (2016) Progress of polymers from renewable resources: furans, vegetable oils, and polysaccharides. Chem Rev 116:1637-1669. https://doi. org/10.1021/acs.chemrev.5b00264

35. Cascone MG, Barbani N, Cristallini C, Giusti P, Ciardelli G, Lazzeri L (2001) Bioartificial polymeric materials based on polysaccharides. J Biomater Sci Polym Ed 12:267-281. https://doi. org/10.1163/156856201750180807

36. Finkenstadt VL (2005) Natural polysaccharides as electroactive polymers. Appl Microbiol Biotechnol 67:735-745. https://doi. org/10.1007/s00253-005-1931-4

37. Fedorov SN, Ermakova SP, Zvyagintseva TN, Stonik VA (2013) Anticancer and cancer preventive properties of marine polysaccharides: some results and prospects. Mar Drugs 11:4876-4901. https://doi.org/10.3390/md11124876 
38. Yamada S, Sugahara K (2008) Potential therapeutic application of chondroitin sulfate/dermatan sulfate. Curr Drug Discov Technol 5:289-301. https://doi.org/10.2174/157016308786733 564

39. Petit E, Delattre C, Papy-Garcia D, Michaud P (2006) Chondroitin sulfate lyases: applications in analysis and glycobiology. Adv Pharmacol 53:167-186. https://doi.org/10.1016/ S1054-3589(05)53008-4

40. Chen Q, Shao X, Ling P, Liu F, Han G, Wang F (2017) Recent advances in polysaccharides for osteoarthritis therapy. Eur J Med Chem 139:926-935. https://doi.org/10.1016/j.ejmec h.2017.08.048

41. Huang G, Huang H (2018) Application of hyaluronic acid as carriers in drug delivery. Drug Deliv 25:766-772. https://doi. org/10.1080/10717544.2018.1450910

42. Gupta RC, Lall R, Srivastava A, Sinha A (2019) Hyaluronic acid: molecular mechanisms and therapeutic trajectory. Front Vet Sci 6:1-24. https://doi.org/10.3389/fvets.2019.00192

43. Yang M, Lin HB, Gong S, Chen PY, Geng LL, Zeng YM et al (2014) Effect of astragalus polysaccharides on expression of TNF- $\alpha$, IL- $1 \beta$ and NFATc4 in a rat model of experimental colitis. Cytokine 70:81-86. https://doi.org/10.1016/j. cyto.2014.07.250

44. Pu X, Ma X, Liu L, Ren J, Li H, Li X et al (2016) Structural characterization and antioxidant activity in vitro of polysaccharides from angelica and astragalus. Carbohydr Polym 137:154-164. https://doi.org/10.1016/j.carbpol.2015.10.053

45. Xue H, Gan F, Zhang Z, Hu J, Chen X, Huang K (2015) Astragalus polysaccharides inhibits PCV2 replication by inhibiting oxidative stress and blocking NF- $\mathrm{KB}$ pathway. Int J Biol Macromol 81:22-30. https://doi.org/10.1016/j.ijbiomac.2015.07.050

46. Yang B, Xiao B, Sun T (2013) Antitumor and immunomodulatory activity of astragalus membranaceus polysaccharides in $\mathrm{H} 22$ tumor-bearing mice. Int J Biol Macromol 62:287-290. https:// doi.org/10.1016/j.ijbiomac.2013.09.016

47. Guo Z, Lou Y, Kong M, Luo Q, Liu Z, Wu J (2019) A systematic review of phytochemistry, pharmacology and pharmacokinetics on Astragali radix: implications for Astragali radix as a personalized medicine. Int J Mol Sci 20:1-44. https://doi.org/10.3390/ ijms20061463

48. Lee DY, Park CW, Lee SJ, Park HR, Seo DB, Park JY et al (2019) Immunostimulating and antimetastatic effects of polysaccharides purified from ginseng berry. Am J Chin Med 47:823-839. https ://doi.org/10.1142/S0192415X19500435

49. Xie JT, Wu JA, Mehendale S, Aung HH, Yuan CS (2004) Anti-hyperglycemic effect of the polysaccharides fraction from American ginseng berry extract in ob/ob mice. Phytomedicine 11:182-187. https://doi.org/10.1078/0944-7113-00325

50. Ullah S, Khalil AA, Shaukat F, Song Y (2019) Sources, extraction and biomedical properties of polysaccharides. Foods. https ://doi.org/10.3390/foods8080304

51. Park SJ, Lee KW, Lim DS, Lee S (2012) The sulfated polysaccharide fucoidan stimulates osteogenic differentiation of human adipose-derived stem cells. Stem Cells Dev 21:2204-2211. https ://doi.org/10.1089/scd.2011.0521

52. Fitton JH, Stringer DN, Karpiniec SS (2015) Therapies from fucoidan: an update. Mar Drugs 13:5920-5946. https://doi. org $/ 10.3390 / \mathrm{md} 13095920$

53. Wang Y, Xing M, Cao Q, Ji A, Liang H, Song S (2019) Biological activities of fucoidan and the factors mediating its therapeutic effects: a review of recent studies. Mar Drugs 17:15-17. https:// doi.org/10.3390/md17030183

54. van Weelden G, Bobi M, Okła K, van Weelden WJ, Romano A, Pijnenborg JMA (2019) Fucoidan structure and activity in relation to anti-cancer mechanisms. Mar Drugs. https://doi. org $/ 10.3390 / \mathrm{md} 17010032$
55. Damonte E, Matulewicz M, Cerezo A (2012) Sulfated seaweed polysaccharides as antiviral agents. Curr Med Chem 11:2399_ 2419. https://doi.org/10.2174/0929867043364504

56. Luo X, Huang S, Luo S, Liao H, Wang Y, Deng X et al (2018) Identification of genes underlying the enhancement of immunity by a formula of lentinan, pachymaran and tremelia polysaccharides in immunosuppressive mice. Sci Rep 8:1-10. https://doi. org/10.1038/s41598-018-28414-w

57. Wang J, Li W, Huang X, Liu Y, Li Q, Zheng Z et al (2017) A polysaccharide from Lentinus edodes inhibits human colon cancer cell proliferation and suppresses tumor growth in athymic nude mice. Oncotarget 8:610-623. https://doi.org/10.18632/oncotarget .13481

58. Bisen PS, Baghel RK, Sanodiya BS, Thakur GS, Prasad GBKS (2010) Lentinus edodes: a macrofungus with pharmacological activities. Curr Med Chem 17:2419-2430. https://doi. org/10.2174/092986710791698495

59. Li X, Ma L, Zhang L (2019) Molecular basis for Poria cocos mushroom polysaccharide used as an antitumor drug in China, vol 163. Elsevier, Amsterdam

60. Li X, He Y, Zeng P, Liu Y, Zhang M, Hao C et al (2019) Molecular basis for Poria cocos mushroom polysaccharide used as an antitumour drug in China. J Cell Mol Med 23:4-20. https://doi. org/10.1111/jcmm.13564

61. Cordero RJB, Frases S, Guimaräes AJ, Rivera J, Casadevall A (2011) Evidence for branching in cryptococcal capsular polysaccharides and consequences on its biological activity. Mol Microbiol 79:1101-1117. https://doi.org/10.111 1/j.1365-2958.2010.07511.x

62. Khalikova E, Susi P, Korpela T (2005) Microb Dextran-Hydrol Enzymes 69:306-325. https://doi.org/10.1128/JMBR.69.2.306

63. Li Q, Williams CG, Sun DDN, Wang J, Leong K, Elisseeff JH (2004) Photocrosslinkable polysaccharides based on chondroitin sulfate. J Biomed Mater Res - Part A 68:28-33. https://doi. org/10.1002/jbm.a.20007

64. Alvarez-Lorenzo C, Blanco-Fernandez B, Puga AM, Concheiro A (2013) Crosslinked ionic polysaccharides for stimuli-sensitive drug delivery. Adv Drug Deliv Rev 65:1148-1171. https://doi. org/10.1016/j.addr.2013.04.016

65. Chourasia MK, Jain SK (2004) Polysaccharides for colon targeted drug delivery. Drug Deliv J Deliv Target Ther Agents 11:129-148. https://doi.org/10.1080/10717540490280778

66. Vandamme TF, Lenourry A, Charrueau C, Chaumeil JC (2002) The use of polysaccharides to target drugs to the colon. Carbohydr Polym 48:219-231. https://doi.org/10.1016/S0144 -8617(01)00263-6

67. Suginta W, Khunkaewla P, Schulte A (2013) Electrochemical biosensor applications of polysaccharides chitin and chitosan. Chem Rev 113:5458-5479. https://doi.org/10.1021/cr300325r

68. Arca HÇ, Günbeyaz M, Şenel S (2009) Chitosan-based systems for the delivery of vaccine antigens. Expert Rev Vaccines 8:937953. https://doi.org/10.1586/erv.09.47

69. Luo Y, Wang Q (2014) Recent development of chitosan-based polyelectrolyte complexes with natural polysaccharides for drug delivery. Int J Biol Macromol 64:353-367. https://doi. org/10.1016/j.ijbiomac.2013.12.017

70. Azzam T, Eliyahu H, Raskin A, Makovitzki A, Barenholz Y, Lineal $\mathrm{M}$ et al (2002) Cationic polysaccharides as vectors for gene delivery. Am Chem Soc Polym Prepr Div Polym Chem 43:671-672

71. Laurienzo P (2010) Marine polysaccharides in pharmaceutical applications: an overview. Mar Drugs 8:2435-2465. https://doi. org $/ 10.3390 / \mathrm{md} 8092435$

72. Zong A, Cao H, Wang F (2012) Anticancer polysaccharides from natural resources: a review of recent research. Carbohydr Polym 90:1395-1410. https://doi.org/10.1016/j.carbpol.2012.07.026 
73. Ji WY, Xun WZ, Ming ZF, Linhardt RJ, Long SP, Qiang ZA (2019) Structure, bioactivities and applications of the polysaccharides from Tremella fuciformis mushroom: a review. Int $\mathbf{J}$ Biol Macromol 121:1005-1010. https://doi.org/10.1016/j.ijbio mac.2018.10.117

74. Zhang M, Cui SW, Cheung PCK, Wang Q (2007) Antitumor polysaccharides from mushrooms: a review on their isolation process, structural characteristics and antitumor activity. Trends Food Sci Technol 18:4-19. https://doi.org/10.1016/j. tifs.2006.07.013

75. Ren L, Perera C, Hemar Y (2012) Antitumor activity of mushroom polysaccharides: a review. Food Funct 3:1118-1130. https://doi.org/10.1039/c2fo10279j

76. Zhao L, Dong Y, Chen G, Hu Q (2010) Extraction, purification, characterization and antitumor activity of polysaccharides from Ganoderma lucidum. Carbohydr Polym 80:783-789. https:// doi.org/10.1016/j.carbpol.2009.12.029

77. Lee IH, Huang RL, Chen CT, Chen HC, Hsu WC, Lu MK (2002) Antrodia camphorata polysaccharides exhibit anti-hepatitis B virus effects. FEMS Microbiol Lett 209:61-65. https:// doi.org/10.1111/j.1574-6968.2002.tb11110.x

78. Paulsen B (2005) Plant polysaccharides with immunostimulatory activities. Curr Org Chem 5:939-950. https://doi. org/10.2174/1385272013374987

79. Pandya U, Dhuldhaj U, Sahay NS (2019) Bioactive mushroom polysaccharides as antitumor: an overview. Nat Prod Res 33:2668-2680. https://doi.org/10.1080/14786419.2018.14661 29

80. Schepetkin IA, Quinn MT (2006) Botanical polysaccharides: macrophage immunomodulation and therapeutic potential. Int Immunopharmacol 6:317-333. https://doi.org/10.1016/j.intim p.2005.10.005

81. Costa LS, Fidelis GP, Cordeiro SL, Oliveira RM, Sabry DA, Câmara RBG et al (2010) Biological activities of sulfated polysaccharides from tropical seaweeds. Biomed Pharmacother 64:21-28. https://doi.org/10.1016/j.biopha.2009.03.005

82. Meng X, Liang H, Luo L (2016) Antitumor polysaccharides from mushrooms: a review on the structural characteristics, antitumor mechanisms and immunomodulating activities. Carbohydr Res 424:30-41. https://doi.org/10.1016/j.carres.2016.02.008

83. Seidi F, Jenjob R, Phakkeeree T, Crespy D (2018) Saccharides, oligosaccharides, and polysaccharides nanoparticles for biomedical applications. J Control Release 284:188-212. https:// doi.org/10.1016/j.jconrel.2018.06.026

84. Wijesekara I, Pangestuti R, Kim SK (2011) Biological activities and potential health benefits of sulfated polysaccharides derived from marine algae. Carbohydr Polym 84:14-21. https://doi. org/10.1016/j.carbpol.2010.10.062

85. Kardošová A, Machová E (2006) Antioxidant activity of medicinal plant polysaccharides. Fitoterapia 77:367-373. https://doi. org/10.1016/j.fitote.2006.05.001

86. De Souza MCR, Marques CT, Guerra Dore CM, Da Silva FRF, Oliveira Rocha HA, Leite EL (2007) Antioxidant activities of sulfated polysaccharides from brown and red seaweeds. J Appl Phycol 19:153-160. https://doi.org/10.1007/s10811-006-9121-z

87. Tseng YH, Yang JH, Mau JL (2008) Antioxidant properties of polysaccharides from Ganoderma tsugae. Food Chem 107:732738. https://doi.org/10.1016/j.foodchem.2007.08.073

88. Yuan JF, Zhang ZQ, Fan ZC, Yang JX (2008) Antioxidant effects and cytotoxicity of three purified polysaccharides from Ligusticum chuanxiong Hort. Carbohydr Polym 74:822-827. https://doi. org/10.1016/j.carbpol.2008.04.040

89. Jin X (2012) Bioactivities of water-soluble polysaccharides from fruit shell of Camellia oleifera Abel.: antitumor and antioxidant activities. Carbohydr Polym 87:2198-2201. https://doi. org/10.1016/j.carbpol.2011.10.047
90. Qiao D, Ke C, Hu B, Luo J, Ye H, Sun Y et al (2009) Antioxidant activities of polysaccharides from Hyriopsis cumingii. Carbohydr Polym 78:199-204. https://doi.org/10.1016/j.carbp ol.2009.03.018

91. Li R, Chen WC, Wang WP, Tian WY, Zhang XG (2010) Antioxidant activity of astragalus polysaccharides and antitumour activity of the polysaccharides and siRNA. Carbohydr Polym 82:240-244. https://doi.org/10.1016/j.carbpol.2010.02.048

92. Jiao G, Yu G, Zhang J, Ewart HS (2011) Chemical structures and bioactivities of sulfated polysaccharides from marine algae. Mar Drugs 9:196-233. https://doi.org/10.3390/md9020196

93. Arad S, Levy-Ontman O (2010) Red microalgal cell-wall polysaccharides: biotechnological aspects. Curr Opin Biotechnol 21:358-364. https://doi.org/10.1016/j.copbio.2010.02.008

94. Mzoughi Z, Abdelhamid A, Rihouey C, Le Cerf D, Bouraoui A, Majdoub H (2018) Optimized extraction of pectin-like polysaccharide from Suaeda fruticosa leaves: characterization, antioxidant, anti-inflammatory and analgesic activities. Carbohydr Polym 185:127-137. https://doi.org/10.1016/j.carbp ol.2018.01.022

95. Nie S, Cui SW, Xie M (2018) Practical applications of bioactive polysaccharides. Bioact Polysaccharides. https://doi.org/10.1016/ b978-0-12-809418-1.00011-3

96. Nayak AK, Ahmed SA, Tabish M, Hasnain MS (2019) Natural polysaccharides in tissue engineering applications. Elsevier, Amsterdam

97. Moradi Z, Kefiran KN (2019) A branched polysaccharide: preparation, properties and applications: a review. Carbohydr Polym. https://doi.org/10.1016/j.carbpol.2019.115100

98. De Jesus Raposo MF, De Morais RMSC, De Morais AMMB (2013) Bioactivity and applications of sulphated polysaccharides from marine microalgae. Mar Drugs 11:233-252. https://doi. org/10.3390/md11010233

99. Mohan K, Ravichandran S, Muralisankar T, Uthayakumar V, Chandirasekar R, Seedevi P et al (2019) Application of marinederived polysaccharides as immunostimulants in aquaculture: a review of current knowledge and further perspectives. Fish Shellfish Immunol 86:1177-1193. https://doi.org/10.1016/j. fsi.2018.12.072

100. Olennikov DN, Kashchenko NI, Chirikova NK, Koryakina LP, Vladimirov LN (2015) Bitter gentian teas: nutritional and phytochemical profiles, polysaccharide characterisation and bioactivity. Molecules 20:20014-20030. https://doi.org/10.3390/molec ules201119674

101. Naveed M (2020) Various evidence-based hypothetical and experimental treatment approaches and their effectiveness against COVID-19 worldwide: a comprehensive literature review. Eurasian J Med Oncol 4:265-285. https://doi.org/10.14744/ ejmo.2020.52538

102. Chen X, Han W, Wang G, Zhao X (2020) Application prospect of polysaccharides in the development of anti-novel coronavirus drugs and vaccines. Int J Biol Macromol 164:331-343. https:// doi.org/10.1016/j.ijbiomac.2020.07.106

103. Kwon PS, Oh H, Kwon SJ, Jin W, Zhang F, Fraser K et al (2020) Sulfated polysaccharides effectively inhibit SARS-CoV-2 in vitro. Cell Discov 6:4-7. https://doi.org/10.1038/s41421-02000192-8

104. Rong CR, Jun LY, Jia CJ, Li LC (2020) A review for natural polysaccharides with anti-pulmonary fibrosis properties, which may benefit to patients infected by 2019-nCoV. Carbohydr Polym 247:116740. https://doi.org/10.1016/j.carbpol.2020.116740

105. Awasthi A, Vishwas S, Corrie L, Kumar RR, Khursheed R, Kaur $\mathrm{J}$ et al (2020) The important role of polysaccharides from a traditional Chinese medicine-lung cleansing and detoxifying decoction against the COVID-19 pandemic 2020. Carbohydr Polym. https://doi.org/10.1016/j.carbpol.2020.116346 
106. Shariatinia Z (2019) Pharmaceutical applications of natural polysaccharides. Elsevier, Amsterdam

107. Tchobanian A, Van Oosterwyck H, Fardim P (2019) Polysaccharides for tissue engineering: current landscape and future prospects. Carbohydr Polym 205:601-625. https://doi.org/10.1016/j. carbpol.2018.10.039

108. Maciel JV, Durigon AMM, Souza MM, Quadrado RFN, Fajardo AR, Dias D (2019) Polysaccharides derived from natural sources applied to the development of chemically modified electrodes for environmental applications: a review. Trends Environ Anal Chem 22:e00062. https://doi.org/10.1016/j.teac.2019.e00062

109. Layek B, Mandal S (2019) Natural polysaccharides for controlled delivery of oral therapeutics: a recent update. Carbohydr Polym. https://doi.org/10.1016/j.carbpol.2019.115617

110. Ren Y, Bai Y, Zhang Z, Cai W, Del Rio FA (2019) The preparation and structure analysis methods of natural polysaccharides of plants and fungi: a review of recent development. Molecules. https://doi.org/10.3390/molecules24173122

111. Saidin NM, Anuar NK, Meor Mohd Affandi MMR (2018) Roles of polysaccharides in transdermal drug delivery system and future prospects. J Appl Pharm Sci 8:141-157. https://doi. org/10.7324/JAPS.2018.8320

112. Van Dam JEG, Van Den Broek LAM, Boeriu CG (2017) Polysaccharides in human health care. Nat Prod Commun 12:821-830. https://doi.org/10.1177/1934578x1701200604

Publisher's Note Springer Nature remains neutral with regard to jurisdictional claims in published maps and institutional affiliations. 